bei verfassungswidrigen Normen eigentlich nur die Nichtigkeitsfolge kennt und keine positive Gestaltungsfunktion des BVerfG vorsieht (\$\$ 78 Rn. 13 ff., 95 Rn. 46 ff.).

Mit seiner politischen Sensibilität trägt das Werk dem besonderen Doppel-Charakter des Bundesverfassungsgerichts als justizförmiges Entscheidungsorgan und politischer Akteur in gelungener Weise Rechnung. Hinzu kommen eine klare Sprache und die eigenständige Positionierung in spannenden Streitfragen, was diesen Kommentar zu einer ebenso interessanten wie wertvollen Bereicherung der verfassungsprozessualen Literatur macht.

Volker M. Haug

\title{
Das Bundesverfassungsgericht und die EU: Positionen auf dem Prüfstand
}

van Ooyen, Robert Christian: Die Staatstheorie des Bundesverfassungsgerichts und Europa, 4. Auflage, Nomos Verlagsgesellschaft, Baden-Baden 2011, 236 Seiten, € 29,-.

Seit langem behandelt Robert Christian van Ooyen die rechtspolitische Stellung moderner Staaten, hier mit Blick auf die Europa-Rechtsprechung des Bundesverfassungsgerichts. Seit 1967 urteilt Karlsruhe über die Stellung des Europarechts. Vermied das Gericht noch im Urteil vom 30. Juli 1952 im Zusammenhang mit der Europäischen Verteidigungsgemeinschaft (BVerfGE 1, S. 396 ff.) Aussagen zur im EVG-Vertrag vorgesehenen Europäischen Politischen Gemeinschaft, befand es am 18. November 1967 im Votum zu den EWG-Verordnungen, das Gemeinschaftsrecht sei eine eigenständige Rechtsquelle (BVerfGE 22, S. 293 ff.), und folgte damit den EuGH-Urteilen vom 5. Februar 1963 in der Rechtssache van Gend \& Loos und vom 15. Juli 1964 in der Rechtssache Costa / ENEL zu dessen absolutem Vorrang. Dies ist der Ausgangspunkt der äußerst straffen Darstellung van Ooyens.

Der Autor beschreibt die relevanten Entscheidungen, wovon im Anhang große Teile oder die Leitsätze abgedruckt sind, leider ohne die Randnummern der Internet-Exemplare bzw. Seitenzahlen der Entscheidungssammlung. Ausführlich behandelt er die „Solange-Beschlüsse“: In „Solange I“ (BVerfGE 37, S. 271 ff.) konstatierte das BVerfG am 29. Mai 1974, mangels europäischen Grundrechtskatalogs könne europäisches Sekundärrecht, Rechtsakte, auch EuGH-Urteile am Grundgesetz überprüfen; dieser Vorbehalt wurde am 22. Oktober 1986 im „Solange II“-Beschluss zurückgestellt. Im Maastricht-Urteil vom 12. Oktober 1993 (BVerfGE 89, S. 155 ff.) ging das Gericht dann ob des vom Autor stringent dargestellten etatistischen Demokratiemodells um den souveränen Staat aus eigenem Recht und das Staatsvolk als homogene politische Einheit. Zugleich wurde damit Karlsruhes Anspruch auf „Augenhöhe“ mit dem EuGH, gegebenenfalls als sein Korrektor formuliert, während am 4. April 2013 Frankreichs Conseil constitutionnel - dem Bundesverfassungsgericht vergleichbar - in der Décision 2013-314P QPC eine Streitfrage dem EuGH vorlegte und Österreichs Verfassungsgericht am 4. Mai 2012 auf der Grundlage der EU-Grundrechtecharta urteilte; das BVerfG hingegen würdigte zur EGMR-Entscheidung in Sachen Görgülü die Europäische Menschenrechtskonvention zu bloß einfachem Recht unterhalb des Grundgesetzes herab (BVerfGE 111, S. 307 ff.). Im Urteil zur Antiterrordatei vom 24. April 2013 (1 BvR 1215/07) kommt es ohne konkreten Anlass zum EuGH-Urteil vom 26. Februar 2013 in der Finnland betreffenden Rechtssache Akerberg Fransson sogar zum Angriff: Im Sinne eines 
kooperativen Miteinanders der beiden Gerichte „darf dieser Entscheidung keine Lesart unterlegt werden, nach der diese offensichtlich als Ultra-Vires-Akt zu beurteilen wäre oder Schutz und Durchsetzung der mitgliedstaatlichen Grundrechte in einer Weise gefährdete, dass dies die Identität der durch das Grundgesetz errichteten Verfassungsordnung in Frage stellte“. Denn das Lissabon-Urteil (BVerfGE 123, S. 267 ff.) macht den souveränen Nationalstaat entgegen der Grundgesetzpräambel und des Europa-Artikels 23 über Art. 79 Abs. 3 GG „verfassungsfest“ gegenüber Europas Integration. „Die Macht des Bundesverfassungsgerichts ist nicht zuletzt ,Deutungsmacht'“, so der Autor (S. 67) zur alt-neuen Trinitätslehre Staat - Souveränität - Demokratie. Es ist das Staatsverständnis der Richter, die in der globalisierten Welt nationalstaatliche Souveränität ins Zentrum rücken. Besondere Aufmerksamkeit widmet van Ooyen den Richtern Ernst-Wolfgang Böckenförde und Paul Kirchhof als prominenten Vertretern dieser Gedankenwelt. Tatsächlich gibt es keinen homogenen deutschen Staat mit schon über einem Fünftel Zuwanderern bei rasch steigender Tendenz. Noch wird er in der sich wandelnden Meinung der Bevölkerung wirklich getragen. Beispielhaft zeigte es jüngst der Sachsen-Anhalt-Monitor 2012, wonach in dem Land mit kaum wahrnehmbarer Ausländerzahl nur 46 Prozent der Befragten voll und ganz, 16 Prozent eher „lieber Bürger/Bürgerin von Deutschland als irgendeinem anderen Land auf der Welt“ sein wollen; in der jüngeren Generation ist die nationalstaatliche Präferenz noch geringer.

In Verkennung der Wirklichkeit leugnet das BVerfG die gesamteuropäische Willensbildung, spricht dem Europäischen Parlament in Unkenntnis des Wahlrechts in Europa - angeblich gelte ein gesamteuropäischer Grundsatz der Zählwertgleichheit - die Parlamentsqualität ab, da Deutschland nur 96 Abgeordnete hat: „Weil die EU eben kein Staat ist, hat sie auch kein souveränes Staatsvolk, sondern nur Unionsbürger und folglich bloß ein ,Hilfsparlament' der Völker.“ (S. 91) Jedoch: Das „Bemühen des BVerfGs, das Unionsrecht unter Rückgriff auf seinen Ursprung völkerrechtlich auszulegen, widerspricht einer Rechtsentwicklung, die ihren ersten prinzipiellen Ausdruck im Verfahren ,van Gend \& Loos' gefunden hat" (S. 96). Noch eklatanter wird Karlsruhes Unwissen im Vergleich der EU etwa mit Indien: 21 in der Verfassung normierte Sprachen, weit über hundert Dialekte, nur die englische Besetzung als historisches Einheitsmerkmal - der Verfassungsrichter Dieter Grimm wagte im persönlichen Gespräch nicht, Indien die Staatsqualität abzusprechen.

In der Praxis robbte das Bundesverfassungsgericht aber immer wieder zurück. Auf Maastricht folgte am 7. Juni 2000 im Beschluss zur Bananenmarktordnung (BVerfGE 102, S. 147 ff.) die Rückkehr zu Solange II. Auf Lissabon folgte der Beschluss vom 6. Juli 2010 zu Mangold / Honeywell (BVerfGE 126, S. 286 ff.), mit dem trotz abweichender Meinung des Richters Herbert Landau die EuGH-Rechtsprechung zum Teilzeit- und Befristungsgesetz keiner ultra vires-Kontrolle unterzogen wurde, was nach Lissabon nahe gelegen hätte. Auch wurden alle der gemeinsamen Wirtschaft und dem Euro geltenden Maßnahmen abgesegnet, wie die von van Ooyen nicht mehr behandelten Beschlüsse zur Europäischen Finanzstabilisierungsfazilität vom 7. November 2011 (BVerfGE 129, S. 24 ff) sowie zum Europäischen Stabilitätsmechanismus (ESM) und Fiskalpakt vom 12. September 2012 (2 BvR 1390/12). Doch werden die Richter, vor allem der Präsident und Vorsitzende des meist zuständigen zweiten Senats Andreas Voßkuhle nicht müde, „rote Linien“ zu nennen, über die hinaus Europas Integration nicht gelangen dürfe - hervorragend, wie van Ooyen die Wellenbewegungen beschreibt.

Das Gericht vollzieht oft mit Verzögerung gesellschaftliche Entwicklungen nach. Noch im Urteil vom 10. Mai 1957 bestätigte es die NS-Gesetze gegen Homosexuelle (BVerfGE 
6, S. 389 ff.), folgt nun aber, so im Beschluss vom 8. August 2012 (1 BvL 16/11), den EuGH-Vorgaben seit dessen Urteil vom 1. April 2008 zur Witwerrente gleichgeschlechtlicher Lebenspartnerschaften. Beim zuletzt im ESM-Beschluss betonten Haushaltsrecht des Parlaments hinken die Karlsruher Richter ebenfalls hinterher: kein Wort verloren sie darüber, dass bei PPP-Projekten den Abgeordneten die Verträge und finanziellen Einzelheiten vorenthalten werden. Karlsruhe wird genug Gelegenheit haben, sich zu Europas Integration neu zu positionieren, wie schon bei den gleichgeschlechtlichen Lebensgemeinschaften. „Ich prüfe Europarecht, ich prüfe nicht, ich prüfe (...) Warten wir also ab, die nächste Entscheidung des BVerfG kommt bestimmt" (S. 109), schließt van Ooyen die 4. Auflage des unverzichtbaren Buchs, das das Bundesverfassungsgericht auf den Prüfstand stellt. Politik beginne mit der Betrachtung der Wirklichkeit, sagte Stuttgarts früherer Ministerpräsident Erwin Teufel. Das gilt auch für die Rechtsprechung.

Erich Röper 